\title{
Hournal of Caneer
}

2010; 1:223-229

Research Paper

(C) Ivyspring International Publisher. All rights reserved

\section{Fusion Imaging: A Novel Staging Modality in Testis Cancer}

\author{
Joseph R. Sterbis ${ }^{1}$, Kevin R. Rice ${ }^{1}$, Marcia C. Javitt², Noah S. Schenkman¹, Stephen A. Brassell1 ${ }^{凶}$ \\ 1. Urology Service, Department of Surgery, Walter Reed Army Medical Center, Washington, DC, USA \\ 2. Department of Radiology, Walter Reed Army Medical Center, Washington, DC, USA
}

$\triangle$ Corresponding author: Stephen A. Brassell, Walter Reed Army Medical Center, Building 2, Ward 56, 6900 Georgia Ave, NW, Washington, DC 20307. Stephen.Brassell@amedd.army.mil; Phone: 202-782-4000; Fax: 202-782-2310

Received: 2010.10.20; Accepted: 2010.11.03; Published: 2010.11.05

\begin{abstract}
Objective: Computed tomography and chest radiographs provide the standard imaging for staging, treatment, and surveillance of testicular germ cell neoplasms. Positron emission tomography has recently been utilized for staging, but is somewhat limited in its ability to provide anatomic localization. Fusion imaging combines the metabolic information provided by positron emission tomography with the anatomic precision of computed tomography. To the best of our knowledge, this represents the first study of the effectiveness using fusion imaging in evaluation of patients with testis cancer.

Methods: A prospective study of 49 patients presenting to Walter Reed Army Medical Center with testicular cancer from 2003 to 2009 was performed. Fusion imaging was compared with conventional imaging, tumor markers, pathologic results, and clinical follow-up.

Results: There were 14 true positives, 33 true negatives, I false positive, and I false negative. Sensitivity, specificity, positive predictive value, and negative predictive value were 93.3, 97.0, 93.3, and $97.0 \%$ respectively. In I I patient scenarios, fusion imaging differed from conventional imaging. Utility was found in superior lesion detection compared to helical computed tomography due to anatomical/functional image co-registration, detection of micrometastasis in lymph nodes (pathologic nodes $<\mathrm{Icm}$ ), surveillance for recurrence post-chemotherapy, differentiating fibrosis from active disease in nodes $<2.5 \mathrm{~cm}$, and acting as a quality assurance measure to computed tomography alone.

Conclusions: In addition to demonstrating a sensitivity and specificity comparable or superior to conventional imaging, fusion imaging shows promise in providing additive data that may assist in clinical decision-making.
\end{abstract}

Key words: Germ Cell, Imaging, Positron Emission Tomography, Staging, Testis Cancer

\section{Introduction}

The incidence of testis cancer has been increasing at an annual rate of $3 \%$, leading to a doubling in cases world-wide over the last 40 years. With the advent of improved staging and treatment there has been a marked decrease in mortality over this time, estimated at $4.5 \%$ for 2009.1 In recent years, positron emission tomography (PET) has been utilized in conjunction with computed tomography (CT) and chest radiographs (CXR) to survey patients for metastatic or recurrent disease. While CT is the standard of care for locating the presence of lymphadenopathy or retroperitoneal masses, its false negative rates have been reported to be as high as $30-59 \% .^{2,3} \mathrm{PET}$, with its ability to identify regions of increased metabolic activity, has been shown to improve the detection of tumor at initial staging and following chemotherapy. ${ }^{4-6}$

First used clinically in 2001, PET/CT scanners combine both modalities into one device, generating 
images that couple the metabolic sensitivity of PET with the precise anatomic detail of CT. ${ }^{7}$ Initial reports in non-small cell lung cancer, malignant lymphoma, and recurrent colorectal cancer suggest benefits in its use. ${ }^{8-10}$ Since $60-70 \%$ of patients with Stage I non-seminomatous germ cell tumors (NSGCT) and $80 \%$ of Stage I seminoma patients do not harbor occult metastatic disease and, thus, do not require adjuvant therapy, PET/CT could reduce the morbidity of testis cancer treatment if it could identify which patients need adjuvant treatment. ${ }^{11,12}$ Furthermore, the utility of PET alone in the evaluation of post-chemotherapy masses suggests another a role for PET/CT in the post-chemotherapy setting. ${ }^{13,14}$ The goal of this study is to provide an initial assessment of the efficacy of fusion imaging with PET/CT in the management of testis cancer.

\section{Methods}

A prospective analysis of 49 patients presenting to Walter Reed Army Medical Center (WRAMC) with an initial diagnosis of testicular cancer between 2003 and 2009 was conducted. Patients underwent conventional imaging evaluation to include $\mathrm{CT}$ abdomen/pelvis, CXR, as well as a full clinical evaluation to include medical history, physical examination, and serum tumor markers. Additionally, fusion imaging with PET/CT was obtained on each patient. The WRAMC Clinical Investigation Committee and $\mathrm{Hu}-$ man Use Committee approved the study. The patients then went on to receive care as dictated by National Clinical Cancer Network (NCCN) guidelines. The clinical utility of PET/CT was determined by prospective outcomes.

Information regarding radiotherapy, retroperitoneal lymph node dissection (RPLND) pathology, and/or chemotherapy course was obtained in appropriate cases. All tissue specimens were reviewed at the Armed Forces Institute of Pathology with secondary review by a genitourinary pathologist at WRAMC.

Routine axial imaging, consisting of CT of the abdomen and pelvis at $5 \mathrm{~mm}$ intervals with oral and intravenous contrast administration was performed in 48 patients (Lightspeed, GE, Fairfield, Connecticut). One patient had an initial non-contrast CT followed by an MRI due to an intravenous iodinated contrast allergy. These images were interpreted by one staff radiologist with expertise in genitourinary imaging. Lymph nodes larger than $1 \mathrm{~cm}$ in diameter were considered pathologic.

All PET/CT imaging was performed at WRAMC (Biograph, Seimens, Munich, Germany) and evaluated by one of four attending nuclear medicine physicians. The CT images obtained with the PET for fusion imaging were without contrast. All patients maintained a low carbohydrate diet for 12 hours prior to the examination and fingerstick glucose levels were determined before radiotracer administration. All patients were examined with a PET/CT upon initial presentation. Those patients that underwent more than one examination did so following treatment (i.e. chemotherapy or RPLND) as part of their follow-up if there was a clinical suspicion of recurrence. SUV values were compared to background vasculature to determine positivity with the final determination of positive uptake made by the attending nuclear medicine physician blinded to adjunctive studies.

For the purposes of calculating sensitivity, specificity and predictive values, a true positive was confirmed by histology obtained at RPLND $(n=3)$ or either positive serum markers or positive CT size criteria $(\mathrm{n}=11)$ in those patients that did not undergo RPLND. A true negative was defined by pathology when available $(\mathrm{n}=15)$ or by negative follow-up accompanying a negative PET/CT $(\mathrm{n}=18)$. False positives $(n=1)$ and negatives $(n=1)$ were defined either by pathologic findings or clinical follow up contrary to initial PET/CT results.

\section{Results}

Between 2003 and 2009, forty-nine patients were enrolled. Median patient age was 27 years (range 19-57 years). Two patients were Hispanic and the others were Caucasian. Median follow-up from initial presentation was 39 months (range 4 to 85 months). Clinical characteristics of the patient population are detailed in Table 1. One patient classified as seminoma had a focus of teratoma and underwent RPLND as primary treatment. One patient classified as NSGCT had pure teratoma stage IIIC(S1) he underwent chemotherapy and subsequent RPLND. Tissue was obtained from retroperitoneal lymph node dissections in 28 patients.

There were 14 true positives, 33 true negatives, 1 false positive, and 1 false negative. Sensitivity, specificity, positive predictive value and negative predictive values are demonstrated in Table 2 . The sole false positive case occurred in a patient who was initially diagnosed with Stage Is NSGCT. Due to elevated tumor markers post operatively, the patient received 3 cycles BEP. Subsequently, he had normal CT scans and tumor markers. At his 12 month follow-up, surveillance imaging revealed a right $1.3 \mathrm{~cm}$ inguinal lymph node, ipsilateral to his prior orchiectomy. PET/CT also indicated increased uptake in this area. Biopsy of the lymph node demonstrated a foreign body giant cell reaction. The sole false negative oc- 
curred in a patient who initially elected to undergo RPLND despite negative CT and PET/CT scans. Pathologic analysis revealed one of 14 lymph nodes containing embryonal carcinoma, confirming a false negative for PET/CT. Of note, four months later, surveillance CT noted a $1.4 \mathrm{~cm}$ suprahilar node with an increased uptake on PET/CT. The patient underwent chemotherapy with full resolution of findings on subsequent imaging for a total follow-up of 42 months.

\section{Table I: Patient Clinical Features}

\begin{tabular}{|l|l|}
\hline Orchiectomy Pathology & No. Pts \\
\hline Seminoma & 15 \\
\hline NSGCT & 34 \\
\hline Clinical Stage & \\
\hline Ia & 22 \\
\hline Ib & 1 \\
\hline Is & 16 \\
\hline IIa & 2 \\
\hline IIb & 1 \\
\hline IIc & 2 \\
\hline IIIa & 2 \\
\hline IIIb & 3 \\
\hline IIIc & 0 \\
\hline Treatment after orchiectomy & \\
\hline Observation & 11 \\
\hline Radiation & 2 \\
\hline Chemotherapy & 8 \\
\hline Chemotherapy + RPLND & 9 \\
\hline RPLND & 16 \\
\hline RPLND + Chemotherapy & 3 \\
\hline
\end{tabular}

Table 2: Sensitivity, specificity, predictive values, and confidence intervals for PET/CT and CT alone

\begin{tabular}{|c|c|c|}
\hline & PET/CT & CT \\
\hline Sensitivity & $93.3 \%(0.66-0.99)$ & $60.0 \%(0.33-0.82)$ \\
\hline Specificity & $97.0 \%(0.83-0.99)$ & $82.3 \%(0.65-0.93)$ \\
\hline $\begin{array}{l}\text { Positive Predictive } \\
\text { Value }\end{array}$ & $93.3 \%(0.66-0.99)$ & $60.0 \%(0.33-0.82)$ \\
\hline $\begin{array}{l}\text { Negative Predictive } \\
\text { Value }\end{array}$ & $97.0 \%(0.83-0.99)$ & $82.3 \%(0.65-0.93)$ \\
\hline
\end{tabular}

CT and PET/CT findings matched in 38 of 49 patients and where they differed, patient care had the potential to be altered in all 11 scenarios (Table 3). After being offered continued surveillance versus treatment, patients 1 and 2, both of whom had positive PET/CT and negative CT findings, elected to undergo chemotherapy. The CT scan for patient 1 had initially been read as negative. However, the PET/CT performed 14 days later identified a $2.6 \mathrm{~cm}$ node with increased radiotracer uptake that was visible on repeat analysis of the initial CT. The post-chemotherapy
PET/CT for both patients demonstrated cessation of increased radiotracer uptake. Patient 3 had a positive CT scan with a $1.5 \mathrm{~cm}$ node packet adjacent to the vena cava. The PET/CT was negative, and the patient elected for surveillance. Serial CT and PET/CT examinations over the ensuing 44 months have shown stable size and finally resolution of mass at last imaging. Patient 4 had a negative CT and positive PET/CT with a $1.8 \mathrm{~cm}$ para-aortic lymph node (standard uptake value (SUV) 11) that could not be identified on co-registered CT images. He elected to undergo chemotherapy and subsequently had normalization of PET images in this area and no future recurrence. Patient 5 had a positive CT and CT/PET for a stage III NSGCT. After receiving chemotherapy the $\mathrm{CT}$ remained positive demonstrating a $1.5 \mathrm{~cm}$ retroperitoneal LN and the PET/CT was negative for metabolic activity. Subsequent RPLND revealed fibrosis only. Patient 6 had a negative CT and a positive PET/CT obtained 18 days later. This scan revealed a $1.5 \mathrm{~cm}$ pre-aortic and a $2.5 \mathrm{~cm}$ left psoas lymph node, SUV's for both were 16. Again, as in Patient 1, review of the original CT indicated presence of these nodes. The patient received chemotherapy and had normalization of imaging subsequently. Patient 7 had a Stage I NSGCT with negative CT and positive PET/CT indicating 1.2 and $0.9 \mathrm{~cm}$ (SUV 3.6) lymph nodes on initial evaluation. He underwent observation and his tumor markers began to rise 2 months after his PET/CT. Repeat CT was still negative. He underwent chemotherapy with resolution of all findings. Patient 8 had Stage I NSGCT and initial CT indicating multiple groups of equivocal lymph nodes (each approximately $1 \mathrm{~cm}$ ) consistent with metastatic disease. His PET/CT and subsequent RPLND were negative. Patient 9 had stage IIIa NSGCT and subsequent chemotherapy. His post-treatment imaging revealed 2 nodes slightly greater than $1.0 \mathrm{~cm}$, and his PET/CT was negative. RPLND revealed fibrosis. Patient 10 initially presented with stage I NSGCT, his CT was negative but CT/PET revealed an $8 \mathrm{~mm}$ para-aortic lymph node (SUV 3.25) (Figure 1). Subsequent RPLND confirmed this to be positive with a mixture of embryonal and teratomatous components. Patient 11 initially presented with Stage IIa NSGCT, his CT and PET/CT at the time of presentation confirmed two para-aortic lymp nodes 2.29 and $2.10 \mathrm{~cm}$ (SUV 17). Chemotherapy was administered and subsequent imaging noted no significant decrease in size of these nodes but they were not metabolically active on PET/CT. Subsequent RPLND revealed fibrosis. Three patients in our series had evidence of masses both on CT and PET/CT with teratoma on pathologic examination of the RPLND specimens. It should be 
noted that in none of these cases was the mass metabolically active, with maximum SUV being 2.2. Of the 12 patients that underwent chemotherapy after a positive PET/CT, all had a repeat PET/CT following chemotherapy which was negative.

While not confirmed histologically, two patients with elevated tumor markers demonstrated uptake on
PET/CT in nodes $<1 \mathrm{~cm}$. After chemotherapy course, the metabolic activity in these regions resolved and no further recurrences were noted. Additionally, one patient had uptake in a sub-centimeter node on PET/CT which subsequently was confirmed to harbor germ cell tumor.
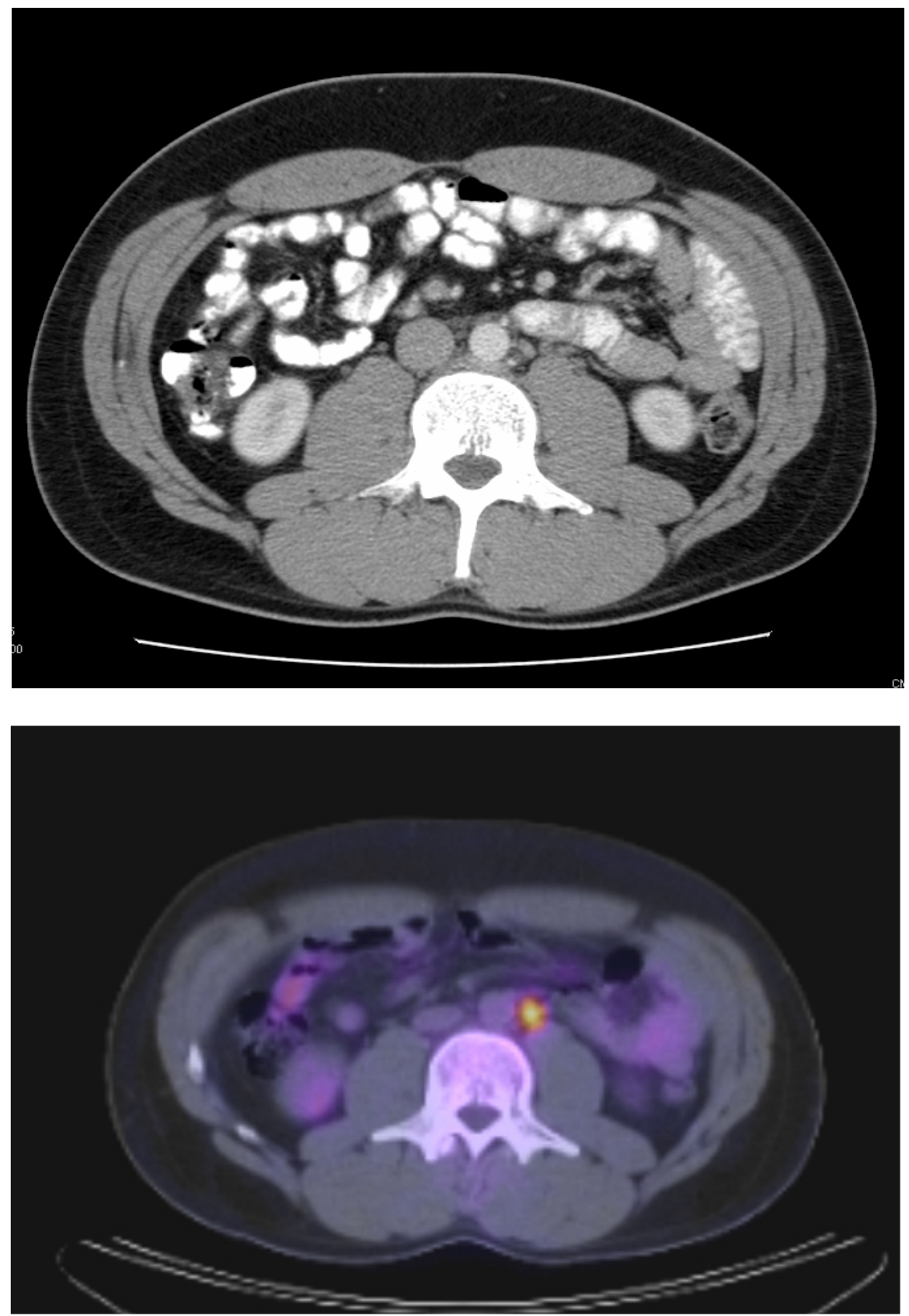

Figure I. A (top image): CT image demonstrating an absence of lymph node enlargement in Patient I0. B (bottom image): Analogous PET/CT image with arrow indicating site of increased FDG metabolism. 
Table 3: Study Subjects with Discordant CT and PET/CT Findings

\begin{tabular}{|c|c|c|c|c|c|}
\hline Patient & $\begin{array}{l}\text { Primary Tumor } \\
\text { Pathology and } \\
\text { Stage }\end{array}$ & CT Findings & PET/CT Findings (SUV) & Adjuvant Therapy & Follow-up \\
\hline 1 & $\begin{array}{l}\text { NSGCT } \\
\text { Stage IIb }\end{array}$ & Negativet & Positive: $2.6 \mathrm{~cm}$ node (16.7) & Chemotherapy & $\begin{array}{l}\text { Normalization of PET/CT fol- } \\
\text { lowing chemotherapy }\end{array}$ \\
\hline 2 & $\begin{array}{l}\text { NSGCT } \\
\text { Stage Ia }\end{array}$ & Negative & Positive (11.1) & Chemotherapy & $\begin{array}{l}\text { Normalization of PET/CT fol- } \\
\text { lowing chemotherapy }\end{array}$ \\
\hline 3 & $\begin{array}{l}\text { Seminoma } \\
\text { Stage Ia }\end{array}$ & $\begin{array}{l}\text { Positive }-1.5 \mathrm{~cm} \text { node } \\
\text { packet }\end{array}$ & Negative & N/A & 44 months with NED \\
\hline 4 & $\begin{array}{l}\text { NSGCT } \\
\text { Stage Ia }\end{array}$ & Negative & Positive: $1.8 \mathrm{~cm}$ node (11) & Chemotherapy & $\begin{array}{l}\text { Normalization of PET/CT fol- } \\
\text { lowing chemotherapy }\end{array}$ \\
\hline 5 & $\begin{array}{l}\text { NSGCT } \\
\text { Stage IIIa }\end{array}$ & $\begin{array}{l}\text { Positive prior to and } \\
\text { following chemothe- } \\
\text { rapy }\end{array}$ & $\begin{array}{l}\text { Positive prior to chemothe- } \\
\text { rapy (5.64), negative follow- } \\
\text { ing chemotherapy }\end{array}$ & $\begin{array}{l}\text { Chemotherapy followed } \\
\text { by RPLND }\end{array}$ & $\begin{array}{l}\text { Fibrosis on pathologic examina- } \\
\text { tion of RPLND Specimen }\end{array}$ \\
\hline 6 & $\begin{array}{l}\text { NSGCT } \\
\text { Stage IIb }\end{array}$ & Negativet & $\begin{array}{l}\text { Positive: } 1.5 \mathrm{~cm} \text { preaortic (16) } \\
\text { and } 2.5 \mathrm{~cm} \text { psoas nodes (16) }\end{array}$ & Chemotherapy & $\begin{array}{l}\text { Normalization of PET/CT fol- } \\
\text { lowing chemotherapy }\end{array}$ \\
\hline 7 & NSGCT Stage Ia & Negative & $\begin{array}{l}\text { Positive: } 1.2 \& 0.9 \mathrm{~cm} \text { nodes } \\
\text { (3.6) }\end{array}$ & Chemotherapy & $\begin{array}{l}\text { Normalization of PET/CT fol- } \\
\text { lowing chemotherapy }\end{array}$ \\
\hline 8 & NSGCT Stage Ia & $\begin{array}{l}\text { Positive - multiple } \\
\text { 1cm lymph nodes }\end{array}$ & Negative & RPLND & $\begin{array}{l}\text { No evidence of metastatic dis- } \\
\text { ease on pathologic examination } \\
\text { of RPLND specimen }\end{array}$ \\
\hline 9 & $\begin{array}{l}\text { NSGCT Stage } \\
\text { IIIa }\end{array}$ & $\begin{array}{l}\text { Post-chemotherapy: } \\
\text { Positive - } 2 \text { nodes } \\
>1.0 \mathrm{~cm}\end{array}$ & Negative & $\begin{array}{l}\text { Chemotherapy followed } \\
\text { by RPLND }\end{array}$ & $\begin{array}{l}\text { Fibrosis on pathologic examina- } \\
\text { tion of RPLND Specimen }\end{array}$ \\
\hline 10 & NSGCT Stage Ia & Negative & $\begin{array}{l}\text { Positive }-8 \mathrm{~mm} \text { para-aortic } \\
\text { node }(3.25)\end{array}$ & RPLND & $\begin{array}{l}\text { Embryonal and teratomatous } \\
\text { metastases on pathologic ex- } \\
\text { amination of RPLND Specimen }\end{array}$ \\
\hline 11 & NSGCT Stage IIa & $\begin{array}{l}\text { Positive prior to and } \\
\text { following chemothe- } \\
\text { rapy }\end{array}$ & $\begin{array}{l}\text { Positive prior to chemothe- } \\
\text { rapy (17); Negative follow- } \\
\text { ing chemotherapy. }\end{array}$ & $\begin{array}{l}\text { Chemotherapy followed } \\
\text { by RPLND }\end{array}$ & $\begin{array}{l}\text { Fibrosis on pathologic examina- } \\
\text { tion of RPLND Specimen }\end{array}$ \\
\hline
\end{tabular}

† Re-examination of CT scan in light of positive PET/CT Findings revealed pathologically enlarged lymph nodes.

\section{Discussion}

Imaging plays a central role in the clinical staging, surveillance, and post-treatment follow up of testicular germ cell tumors. While CT and CXR have served as the standards for these evaluations, recent studies have demonstrated the utility of PET.4,5,13-16 The biochemical foundation for PET is the increased glucose metabolism characteristic of malignant tissues, assayed in PET via fluorine-18 fluorodeoxyglucose (FDG), a radiolabeled glucose analogue. Due to its high cellular activity, testis cancer would be an ideal candidate for an imaging modality that incorporates this concept.

Assessments of PET alone for the initial clinical staging of germ cell tumors have demonstrated sensitivities and specificities ranging from $70-87 \%$ and 94-100\%, respectively, while CT alone has produced sensitivities of $37-100 \%$ and specificities of $58-100 \% .4,5,15-17$ The performance of PET/CT fusion imaging in this pilot study was consistent with and in some cases superior to these findings. As demonstrated in the 11 index patients listed, PET/CT provides additive information that may positively impact decision-making.

In the post-chemotherapy setting, CT cannot distinguish between viable tumor, fibrosis, and mature teratoma. PET has been shown to identify viable tumor in residual masses for both NSGCT and seminoma. ${ }^{13,14}$ In addition to distinguishing tumor from fibrosis or teratoma, Sugawara et al utilized PET kinetic rate constants to differentiate mature teratoma from fibrosis and necrosis. ${ }^{18}$ In our analysis, all teratomatous masses were metabolically negative on PET/CT. However, fusion imaging may still play a role in deciding between chemotherapy or surgery for the initial management of retroperitoneal masses by using metabolic activity as one additional data point. It may also have utility in surgical planning and consideration of an additional cycle or salvage chemotherapy for patients with post-chemotherapy masses. When considering this application, one should consider the findings of Cremerius et al, who described a high rate of false negative PET scans within 2 weeks following chemotherapy, a finding that was echoed by Hain and colleagues.6,19 Given that both PET alone and PET/CT use the same technology for detection of glucose metabolism, a minimum 2 week waiting period between the completion of chemotherapy and performance of PET/CT is prudent.

Another application to consider is in the surveillance of post-chemotherapy patients. In this analysis, there were 12 patients that underwent post-chemotherapy PET/CT following a pre-chemotherapy positive PET/CT. All had negative PET/CT evaluations and none have demonstrated 
disease recurrence at a mean follow-up of 51 months. These findings support the role for PET/CT in this setting.

Sugawara and colleagues expressed concern regarding the capacity of PET to identify residual tumors smaller than $2 \mathrm{~cm} .{ }^{18}$ Similarly, it has been posited that poor spatial resolution limits PET detection of disease in very small masses or lymph nodes..$^{20}$ Our data offer some promise that PET/CT's combination of the metabolic sensitivity of PET with the anatomic accuracy of CT may provide enhanced detection of early disease. Specifically, 3 patients had positive PET/CT's in the presence of negative CT alone. One had pathologic correlation and the other two demonstrated treatment response in these nodes. This suggests an ability of PET/CT to detect disease before it would be identified by traditional methods.

Since the majority of patients with low stage seminoma and NSGCT do not require adjuvant treatment, the potential of PET/CT to identify such patients offers a significant potential benefit. Patient 3 , who elected to undergo surveillance of a $1.5 \mathrm{~cm}$ node group based upon a negative PET/CT, has experienced 44 months without either adjuvant therapy or disease recrudescence, providing an example of the potential of PET/CT to reduce the numbers of patients subjected to the morbidity of adjuvant therapy. In addition to Patient 3, PET/CT had the potential to abrogate additional therapy in 4 other instances as noted above (Patients 5, 8,9 , and 11) where nodes all < $2.5 \mathrm{~cm}$ demonstrated no metabolic activity and demonstrated fibrosis on RPLND.

Further potential benefits of PET/CT are in the comprehensive imaging of the chest. Controversy in this arena exist, but whole lung tomography can alter treatment decisions in approximately $3 \%$ of patients over chest $x$-ray alone. ${ }^{21}$ It can also limit the need to do additive studies in the setting of a positive plain chest x-ray. Furthermore, PET/CT does not use IV contrast which can be complicated by allergic and other adverse reactions. Low-osmolality ionic and nonionic contrast media now in common use are associated with a lower overall incidence of adverse effects than previous high osmolality agents. Allergic reactions are still noted to occur in $4-8 \%$ of patients. ${ }^{22}$ Serious contrast reactions including anaphylaxis are seen in 1 or 2 per 1,000 examinations using high osmolality contrast media and in 1 or 2 per 10,000 examinations using low-osmolality contrast media.22,23 Contrast induced nephrotoxicity is probably related to the degree of pre-existing renal disease and hydration with reported rates between 2-7\%, but its actual prevalence is unknown. ${ }^{22,23}$
PET/CT can provide superior lesion detection compared to helical CT due to anatomical/functional image registration, thereby, identifying nodes with micrometastases that are below the morphologic size criteria used for nodal detection with CT alone. PET/CT may also highlight and lead to detection of nodes otherwise missed on routine CT due to oversight, obscuration by tortuous adjacent blood vessels, or overlying bowel.

There are limitations to PET/CT. Image registration may be hampered by artifacts induced by patient motion, respiratory motion, or by metallic implants. SUV levels obtained by manually drawing regions of interest, based upon a percentage of the maximum SUV, or an absolute value of the SUV may lead to potential measurement errors. Areas with high physiologic activity such as the liver may obscure small lesions. Recent chemo or radiation therapy may limit the sensitivity of PET/CT. Oral and IV contrast for CT alone may lead to unwanted image artifacts on PET/CT. It is important to recognize that fusion imaging with PET/CT is not accurate for nodes $<0.8 \mathrm{~cm}$ largely due to partial volume effects. ${ }^{24}$ Coupled with the risk of false positive PET/CT due metabolically active infection or inflammation, this imaging modality should not substitute for sound clinical judgment. However, complex clinical decisions benefit from additive sources of data. PET/CT can be a useful adjunct for decision making by being one of those sources. Further multi-institutional investigation with a larger patient cohort is needed to further define its role.

\section{Conclusions}

Accurate staging of testicular germ cell tumors is essential to guide patient counseling and selection of appropriate therapy. While CT and chest $x$-ray are the current standard of care, PET has recently been utilized for both lesion detection and tumor staging. This is the first documented evaluation of fusion imaging with PET/CT in testis cancer which suggests that combining these two imaging modalities may afford superior detection and localization of tumor as compared with either one alone. Identification of sub-centimeter nodal micro-metastases at initial staging, surveillance for recurrence, distinguishing active tumor from teratoma or fibrosis, and appropriate triage of patients for primary or secondary therapy are promising benchmarks for future investigations of $\mathrm{PET} / \mathrm{CT}$ in the evaluation of testis cancer.

\section{Acknowledgements}

The authors would like to thank the Urology Service at Walter Reed Army Medical Center. 
The views expressed in this article are those of the authors and do not reflect the official policy of the Department of the Army, Department of Defense, or the U.S. Government.

\section{Conflict of Interest}

The authors have declared that they have no conflicts of interest to disclose.

\section{References}

1. American Cancer Society: Cancer Facts \& Figures 2009. Atlanta, GA: American Cancer Society, 2009.

2. Fernandez EB, Moul JW, Foley JP, Colon E, McLeod DG. Retroperitoneal imaging with third and fourth generation computed axial tomography in clinical stage I nonseminomatous germ cell tumors. Urology. 1994; 44: 548-52.

3. McLeod DG, Weiss RB, Stablein DM, et al. Staging relationships and outcome in early stage testicular cancer: a report from the Testicular Cancer Intergroup Study. J Urol. 1991; 145: 1178-83.

4. Albers P, Bender H, Yilmaz H, Schoeneich G, Biersack HJ, Mueller SC. Positron emission tomography in the clinical staging of patients with Stage I and II testicular germ cell tumors. Urology. 1999; 53: 808-11.

5. Hain SF, O'Doherty MJ, Timothy AR, Leslie MD, Partridge SE, Huddart RA. Fluorodeoxyglucose PET in the initial staging of germ cell tumours. Eur J Nucl Med. 2000; 27: 590-4.

6. Hain SF, O'Doherty MJ, Timothy AR, Leslie MD, Harper PG, Huddart RA. Fluorodeoxyglucose positron emission tomography in the evaluation of germ cell tumours at relapse. Br J Cancer. 2000; 83: 863-9.

7. von Schulthess GK, Steinert HC, Hany TF. Integrated PET/CT: current applications and future directions. Radiology. 2006; 238: 405-22.

8. Lardinois D, Weder W, Hany TF, et al. Staging of non-small-cell lung cancer with integrated positron-emission tomography and computed tomography. N Engl J Med. 2003; 348: 2500-7.

9. Metser U, Goor O, Lerman H, Naparstek E, Even-Sapir E. PET-CT of extranodal lymphoma. AJR Am J Roentgenol. 2004; 182: 1579-86.

10. Cohade C, Osman M, Leal J, Wahl RL. Direct comparison of (18)F-FDG PET and PET/CT in patients with colorectal carcinoma. J Nucl Med. 2003; 44: 1797-803.

11. Spermon JR, Roeleveld TA, van der Poel HG, et al. Comparison of surveillance and retroperitoneal lymph node dissection in Stage I nonseminomatous germ cell tumors. Urology. 2002; 59: 923-9.

12. Horwich A, Alsanjari N, A'Hern R, Nicholls J, Dearnaley DP, Fisher C. Surveillance following orchidectomy for stage I testicular seminoma. Br J Cancer. 1992; 65: 775-8.

13. Stephens AW, Gonin R, Hutchins GD, Einhorn LH. Positron emission tomography evaluation of residual radiographic abnormalities in postchemotherapy germ cell tumor patients. J Clin Oncol. 1996; 14: 1637-41.

14. De Santis M, Bokemeyer C, Becherer A, et al. Predictive impact of 2-18fluoro-2-deoxy-D-glucose positron emission tomography for residual postchemotherapy masses in patients with bulky seminoma. J Clin Oncol. 2001; 19: 3740-4.

15. Cremerius U, Wildberger JE, Borchers $H$, et al. Does positron emission tomography using 18-fluoro-2-deoxyglucose improve clinical staging of testicular cancer?--Results of a study in 50 patients. Urology. 1999; 54: 900-4.

16. Lassen U, Daugaard G, Eigtved A, Hojgaard L, Damgaard K and Rorth M: Whole-body FDG-PET in patients with stage I non-seminomatous germ cell tumours. Eur J Nucl Med Mol Imaging. 2003;30: 396-402

17. Hilton S, Herr HW, Teitcher JB, Begg CB and Castellino RA: CT detection of retroperitoneal lymph node metastases in patients with clinical stage I testicular nonseminomatous germ cell cancer: assessment of size and distribution criteria. AJR Am J Roentgenol. 1997;169: 521-5

18. Sugawara Y, Zasadny KR, Grossman HB, Francis IR, Clarke MF and Wahl RL: Germ cell tumor: differentiation of viable tumor, mature teratoma, and necrotic tissue with FDG PET and kinetic modeling. Radiology. 1999;211: 249-56

19. Cremerius U, Effert PJ, Adam G, Sabri O, Zimmy M, Wagenk-necht $G$, Jakse $G$ and Buell U: FDG PET for detection and therapy control of metastatic germ cell tumor. J Nucl Med. 1998;39: 815-22

20. Kumar R, Zhuang $\mathrm{H}$ and Alavi A: PET in the management of urologic malignancies. Radiol Clin North Am 2004. 42: 1141-53

21. Jochelson MS, Garnick MB, Balikian JP and Richie JP: The effi-cacy of routine whole lung tomography in germ cell tumors. Cancer. 1984;54: 1007-9

22. Singh J and Daftary A: Iodinated contrast media and their ad-verse reactions. J Nucl Med Technol. 2008;36: 69-74

23. American College of Radiology. Manual on Contrast Media, Version 6. US: American College of Radiology, 2008.

24. Lin E, Abass A. PET and PET/CT, A Clinical Guide. New York, NY: Thieme Medical Publishers, 2005. 